\title{
Cortical screws used to rescue failed lumbar pedicle screw construct: a biomechanical analysis
}

\author{
Graham C. Calvert, MD, Brandon D. Lawrence, MD, Amir M. Abtahi, MD, Kent N. Bachus, PhD, \\ and Darrel S. Brodke, MD
}

Department of Orthopaedics, Orthopaedic Bioengineering Laboratory, University of Utah, Salt Lake City, Utah

\begin{abstract}
OBJECT Cortical trajectory screw constructs, developed as an alternative to pedicle screw fixation for the lumbar spine, have similar in vitro biomechanics. The possibility of one screw path having the ability to rescue the other in a revision scenario holds promise but has not been evaluated. The objective in this study was to investigate the biomechanical properties of traditional pedicle screws and cortical trajectory screws when each was used to rescue the other in the setting of revision.
\end{abstract}

METHODS Ten fresh-frozen human lumbar spines were instrumented at L3-4, 5 with cortical trajectory screws and 5 with pedicle screws. Construct stiffness was recorded in flexion/extension, lateral bending, and axial rotation. The L-3 screw pullout strength was tested to failure for each specimen and salvaged with screws of the opposite trajectory. Mechanical stiffness was again recorded. The hybrid rescue trajectory screws at $\mathrm{L}-3$ were then tested to failure.

RESULTS Cortical screws, when used in a rescue construct, provided stiffness in flexion/extension and axial rotation similar to that provided by the initial pedicle screw construct prior to failure. The rescue pedicle screws provided stiffness similar to that provided by the primary cortical screw construct in flexion/extension, lateral bending, and axial rotation. In pullout testing, cortical rescue screws retained $60 \%$ of the original pedicle screw pullout strength, whereas pedicle rescue screws retained $65 \%$ of the original cortical screw pullout strength.

CONCLUSIONS Cortical trajectory screws, previously studied as a primary mode of fixation, may also be used as a rescue option in the setting of a failed or compromised pedicle screw construct in the lumbar spine. Likewise, a standard pedicle screw construct may rescue a compromised cortical screw track. Cortical and pedicle screws each retain adequate construct stiffness and pullout strength when used for revision at the same level.

http://thejns.org/doi/abs/10.3171/2014.10.SPINE14371

KEY WORDS cortical screw; pedicle screw; instrumentation; failed fixation; pullout strength; stiffness; rescue; salvage; arthrodesis; lumbar spine; technique

$\mathrm{C}$ URRENTLY, pedicle screw instrumentation is widely accepted as the mainstay of lumbar spinal inListrumentation and is used to treat a wide range of spinal disorders. Biomechanical studies have shown that pedicle screws obtain most of their purchase in the trabecular and subcortical bone of the pedicle rather than in the dense cortical bone. ${ }^{11,21}$

Recently, cortical trajectory screws were developed as an alternative to traditional pedicle screw fixation in the lumbar spine. In contrast to traditional lumbar pedicle screws, cortical trajectory screws follow a caudal to cephalad and medial to lateral trajectory, which takes ad- vantage of a mostly cortical path that travels away from the midline neural elements. Cortical trajectory screws also have a more medial point of insertion than traditional pedicle screws, which minimize soft-tissue dissection and intraoperative retraction and may limit perioperative morbidity. This trajectory has the advantage of increased cortical bone contact, even though the path through bone is somewhat shorter, which increases screw purchase and has therefore been proposed as an alternative means of instrumentation in the osteoporotic spine. ${ }^{27}$

Cortical screws have been shown to be biomechanically equivalent to traditional pedicle screws in pullout strength

ABBREVIATIONS DEXA = dual-energy $x$-ray absorptiometry; PMMA = polymethylmethacrylate.

SUBMITTED April 14, 2014. ACCEPTED October 23, 2014.

INCLUDE WHEN CITING Published online December 5, 2014; DOI: 10.3171/2014.10.SPINE14371.

DISCLOSURE The authors report no conflict of interest concerning the materials or methods used in this study or the findings specified in this paper. Dr. Brodke is a consultant for, owns stock in, and receives royalties from Amedica; is a consultant for and receives royalties from DePuy; and receives royalties from Medtronic. 
and toggle testing. ${ }^{27}$ In a recent cadaveric biomechanical study, cortical screw fixation provided approximately the same stability as pedicle screw fixation regardless of the presence of interbody support. ${ }^{24}$

While studies have shown the biomechanical similarities between pedicle and cortical screws in pullout strength, toggle, and stiffness, no researcher has examined the possibility of one screw path having the ability to rescue the failure of the other. The aim of this study was to investigate the ability of a cortical screw to rescue a failed pedicle screw track and a pedicle screw to rescue a failed cortical screw track, without extension or augmentation of the fixation in either case.

\section{Methods}

Biomechanical testing was conducted on 10 fresh-frozen nonosteoporotic human lumbar spines (L2-5). Specimens showed no signs of neoplastic, traumatic, congenital, or degenerative conditions on screening radiographs. Dual-energy x-ray absorptiometry (DEXA) scans of each specimen were obtained prior to biomechanical testing, and no osteoporotic specimens were included in our analysis. Specimens were obtained from 6 males and 4 females, with a mean age of 54 years (range 38-68 years) at death. Over a period of 45 days, specimens were received, instrumented, and tested in sequence as they became available. Specimens were assigned to instrumentation groups in an effort to balance the DEXA scores between the two groups.

Each specimen was first dissected free of surrounding soft-tissue muscle and fat with careful attention to preserve ligamentous structures, facet capsules, and discoligamentous complexes. The specimens were then potted in cylindrical fixtures using a commercially available bonding material (Bondo, 3M Company). Both L-3 and L-4 were instrumented, in 5 specimens with $4.5 \times 30-\mathrm{mm}$ MAST MIDLF cortical trajectory screws (Medtronic Inc.; Fig. 1A) and in the other 5 specimens with $6.5 \times 45-\mathrm{mm}$ CD Horizon Solera pedicle trajectory screws (Medtronic Inc.; Fig. 1B). The L-3 and L-4 levels were chosen for instrumentation because they have similar pedicle diameters and because doing so allowed the adjacent L-2 and L-5 segments to be potted for mechanical testing. Traditional pedicle screws and cortical trajectory screws were placed according to previously described techniques (Fig. 2). ${ }^{19,20,27}$ Pedicle screws were undertapped by $1 \mathrm{~mm}$, and cortical trajectory screws were not tapped. Fluoroscopic imaging was used to confirm correct screw placement. After screw insertion but before rod insertion, specimens were preconditioned in flexion/extension, lateral bending, and axial rotation for 30 cycles in each axis. ${ }^{2}$ Screw and rod constructs were then completed with $4.75-\mathrm{mm} \mathrm{CoCr}$ rods (Medtronic Inc.). Using a custom-made 4-axis 3D pneumatic spine testing apparatus and a 5-Nm nondestructive load in flexion/extension, lateral bending, and axial rotation at a rate of $0.1 \mathrm{~Hz}$, we performed stiffness testing on each specimen (Fig. 3 left). ${ }^{1-4,8-10,28}$ The spine testing apparatus is capable of exerting a force about one axis while keeping all other forces at a minimum in order to achieve close to pure moment testing. Three-dimen-
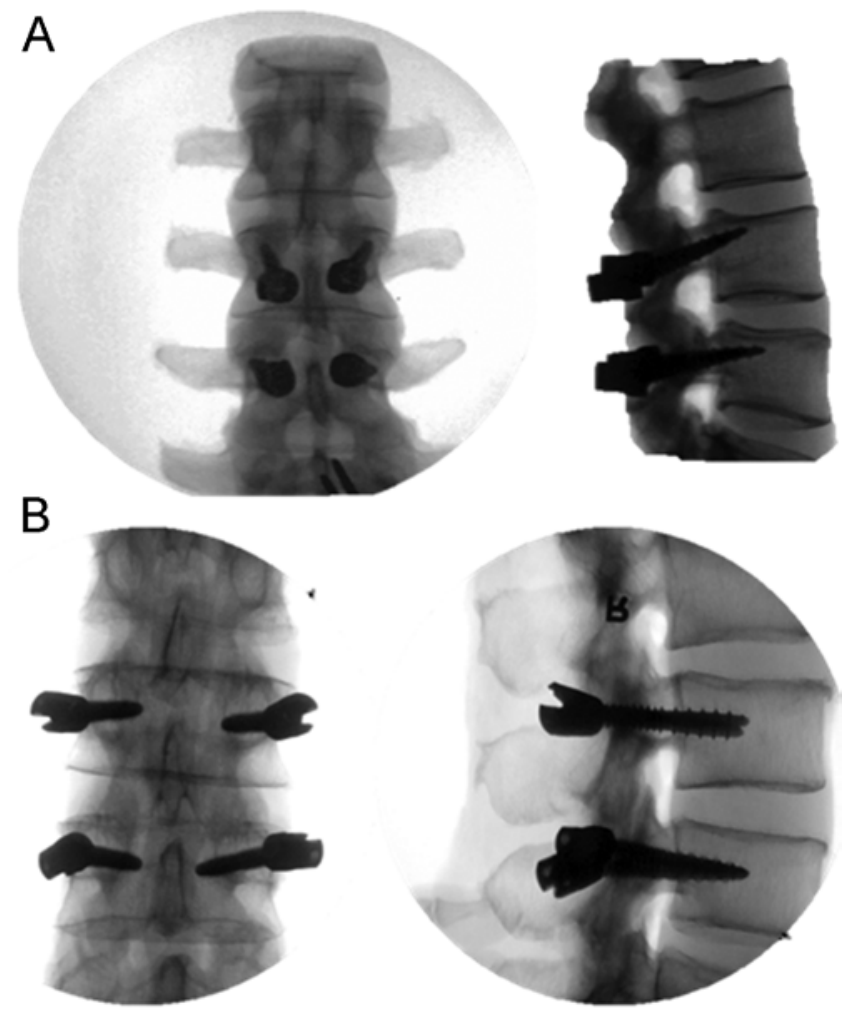

FIG. 1. A: Initial cortical screw construct (pre-rod insertion), anteroposterior (left) and lateral (right) views. B: Initial pedicle screw construct (pre-rod insertion), anteroposterior (left) and lateral (right) views.

sional displacements were recorded using the Optotrak system (model 3020, Northern Digital Inc.; Fig. 3 right). Five cycles were performed for each stiffness measurement, with the final stiffness value $(\mathrm{Nm} /$ degree) based on the average of the final two readings.

Following mechanical stiffness testing, the bilateral L-3 screws for each specimen were tested to failure with a coaxial pullout test, and the load required for failure was recorded for each screw (model 1331, Instron Corp.) with $\mathrm{a} \pm 5$-kN electronically calibrated load cell (model 2518103 , Instron Corp.), controlled with a companion software package (Console Version 8 using an Instron FastTrack 8800 controller). The failed screw track was then salvaged with a screw of the opposite trajectory, and rods were reinserted to create a hybrid construct (Fig. 4). The specimen was then put through the same mechanical stiffness tests and recordings as outlined above. At the conclusion of kinematic testing, the bilateral hybrid rescue trajectory screws at L-3 were tested to failure with a coaxial pullout test as described above.

Data analysis was performed using Microsoft Excel software, and data were statistically compared using the appropriate paired t-test or Student t-test. Statistical significance was set a priori to $\mathrm{p}=0.05$.

\section{Results}

The mean bone mineral density at L3-4 was $1.28 \pm$ $0.20 \mathrm{~g} / \mathrm{cm}^{2}$ across all specimens. The mean bone mineral 
density measurements were $1.24 \pm 0.17$ and $1.30 \pm 0.22 \mathrm{~g} /$ $\mathrm{cm}^{2}$ for the initial cortical and pedicle screw groups, respectively $(p>0.05)$. There were no significant differences in stiffness in flexion/extension or axial rotation between the initial pedicle screw construct and the subsequent hybrid construct with cortical rescue screws; however, a significant difference was noted in lateral bending (Tables 1 and 2 and Fig. 5). There were no significant differences in stiffness in flexion/extension, lateral bending, or axial rotation between the initial cortical screw construct and the subsequent hybrid construct with pedicle rescue screws (Tables 1 and 2 and Fig. 6). Similarly, there were no significant differences in stiffness in flexion/extension, lateral bending, or axial rotation between the hybrid construct with cortical rescue screws and the hybrid constructs with pedicle rescue screws (Tables 1 and 2). In pullout testing, the initial L-3 pedicle screws failed at $1501.7 \mathrm{~N}$, and the subsequent L-3 cortical rescue screws failed at $839.2 \mathrm{~N}$. The initial L-3 cortical screws failed at $1909.4 \mathrm{~N}$, and the subsequent pedicle rescue screws failed at $1148.4 \mathrm{~N}$ (Fig. 7). The L-3 cortical rescue screws retained an average of $60 \%$ of the original pedicle screw pullout strength, and the L-3 pedicle rescue screws retained an average of $65 \%$ of the original cortical screw pullout strength.

\section{Discussion}

Salvaging a loose or compromised pedicle screw may be necessary for a number of reasons, including errors in screw placement, hardware failure, or pseudarthrosis. ${ }^{7,15}$ It is important for the spine surgeon to be familiar with a variety of techniques for screw salvage.

A number of pedicle screw salvage techniques have been described in the literature. One of the more common strategies involves using a screw of greater diameter and/or length. ${ }^{26}$ Augmentation with substances such as polymethylmethacrylate (PMMA), calcium phosphate, hydroxyapatite, and carbonated apatite cement has also been shown to be an effective means of pedicle screw salvage. ${ }^{18,22,23,30}$ Although effective, augmentation with foreign substances, especially PMMA, could lead to neurological injury if extravasation outside of the pedicle and/ or vertebral body occurs. ${ }^{12,29}$ These substances may also be difficult to remove and may increase the risk of subsequent pedicle fracture. ${ }^{6}$ The use of allograft bone augmentation in the form of "matchsticks" or "plugs" for pedicle screw fixation has been studied in the laboratory setting and has been shown to be inferior to other augmentation techniques..$^{5,25}$ Additionally, there is concern, based on the results of other studies, that allograft bone may be quickly resorbed after surgery, causing the pedicle screw to lose fixation. ${ }^{13}$

Another option for salvaging a compromised pedicle screw is to use a different screw trajectory or insertion technique. This strategy has been investigated in the thoracic spine. Yüksel et al. investigated the pullout resistance of thoracic extrapedicular screws used in a salvage procedure and demonstrated a restored pullout strength to $65 \% \pm 30 \%$ of that of intrapedicular screws. ${ }^{31}$ Lehman and colleagues demonstrated, in a cadaveric study, that using the anatomical trajectory for thoracic pedicle screw salvage obtained $62 \%$ of the maximal insertional torque
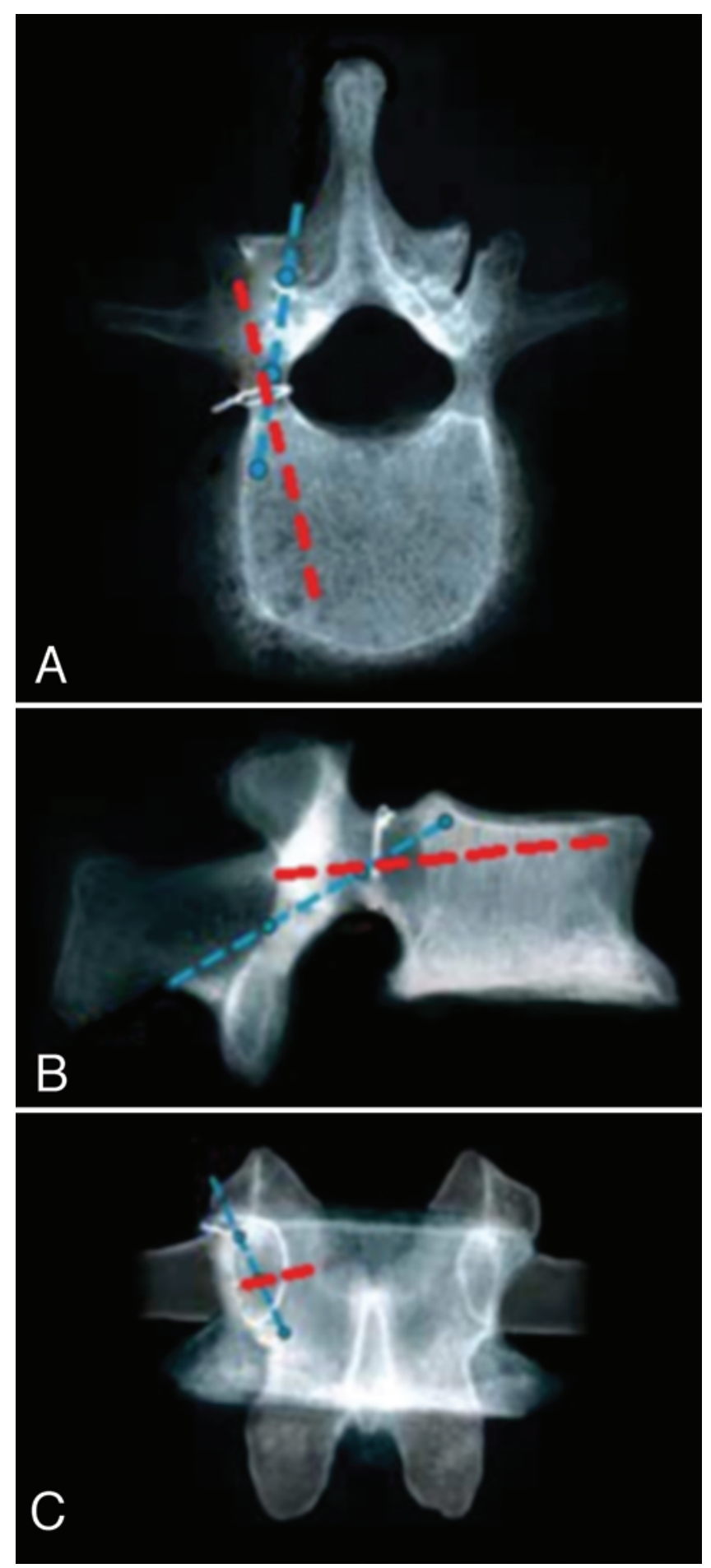

FIG. 2. Pedicle (red lines) and cortical (blue lines) screw trajectories. Axial (A), sagittal (B), and coronal (C) views. Figure is available in color online only.

achieved with initial fixation using the straight-forward trajectory. ${ }^{16,17}$

Cortical trajectory screws have been studied as an alternative to traditional pedicle screws for primary fixation; ${ }^{20,24,27}$ however, the present study is the first in which 


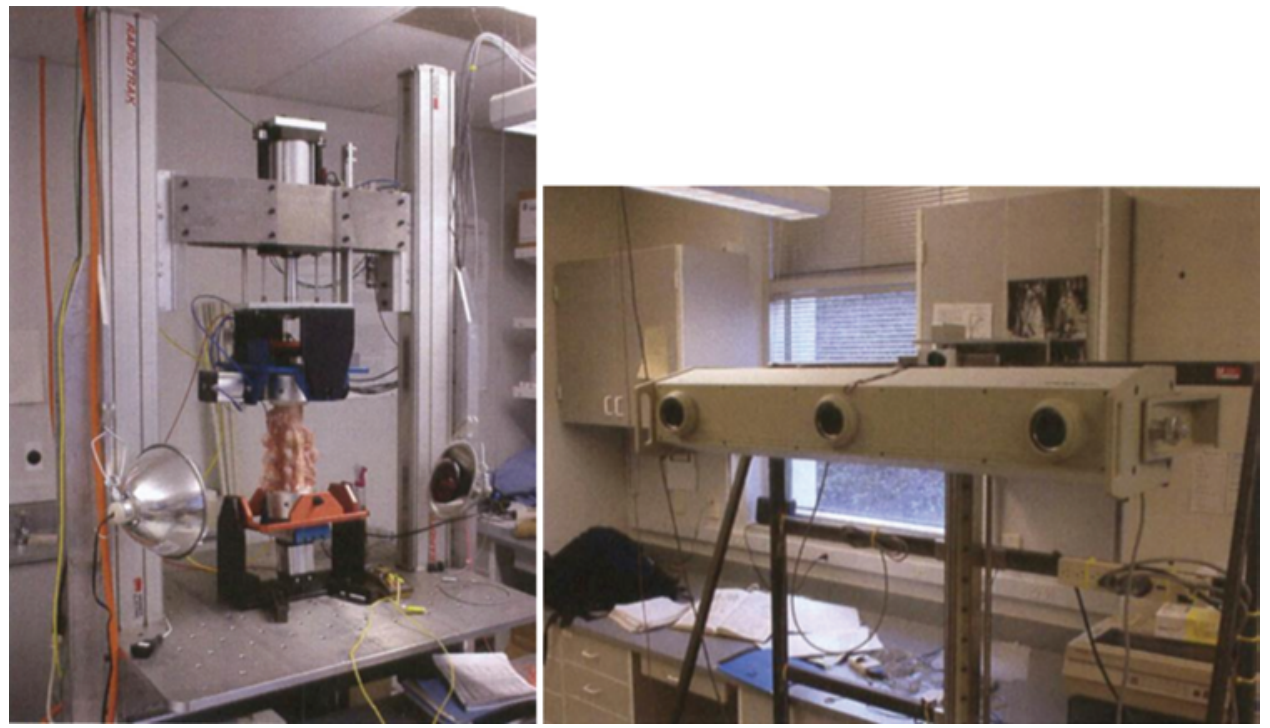

FIG. 3. Left: Orthopaedic Research Laboratory custom-made 4-axis 3D pneumatic spine testing apparatus. Right: Optotrak system. Figure is available in color online only.

their potential use as a rescue option has been evaluated in the setting of a failed or compromised pedicle screw in the lumbar spine. Our findings revealed that cortical trajectory screws averaged $839.2 \mathrm{~N}$ of pullout force when used to rescue a failed pedicle screw. While pullout methods vary among studies, the absolute pullout value in our study is equal to or higher than the average raw pullout values reported for pedicle screws in control groups from other biomechanical studies..$^{14,22,30}$ There were no significant differ-

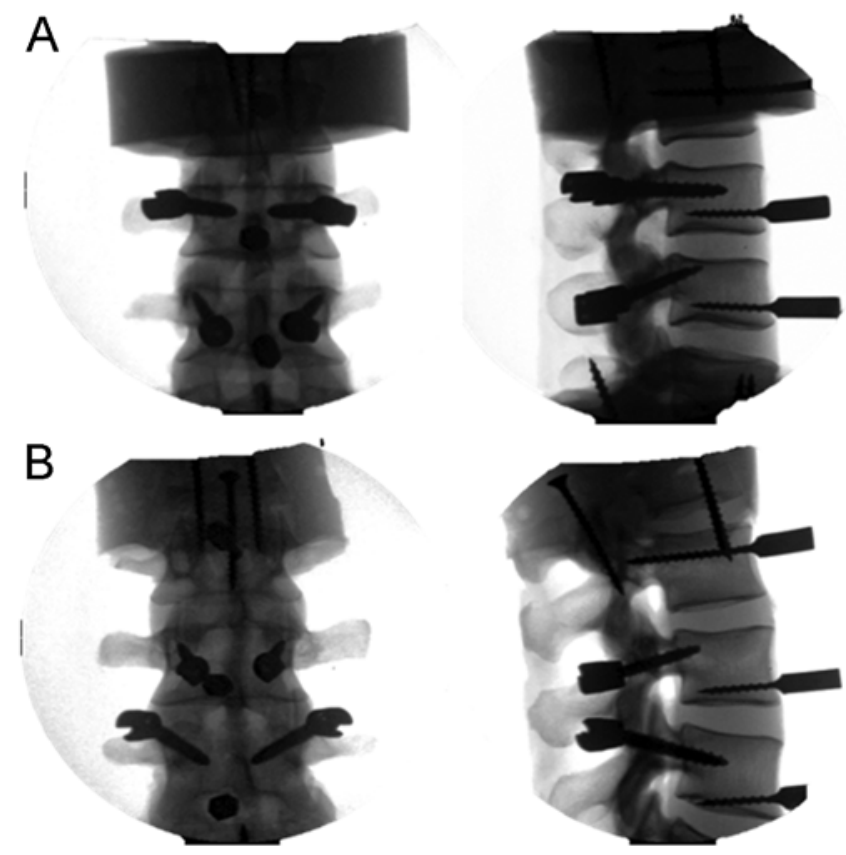

FIG. 4. A: Cortical screw construct with rescue pedicle screw at L-3, anteroposterior (left) and lateral (right) views. B: Pedicle screw construct with rescue cortical screw at L-3, anteroposterior (left) and lateral (right) views. ences in stiffness testing in flexion/extension or axial rotation between the initial pedicle screw construct and the subsequent hybrid construct with cortical rescue screws. A significant difference in stiffness in lateral bending was noted between the initial pedicle screw construct and the subsequent hybrid construct with cortical rescue screws, although this difference was relatively small. These findings suggest that the use of cortical trajectory screws to salvage a failed pedicle screw track is one option among many. As with any rescue method, there is a loss of initial strength; however, this particular option offers safe screw placement, as it is directed away from the neural elements. When utilizing this option, however, the surgeon should note that the head of the rescue screw is not collinear with screws of the opposite trajectory. This may pose a challenge with rod placement in a multilevel construct, and offset connectors may be used to overcome this technical issue.

Findings in this study also suggested that a compromised cortical screw track can be rescued with a pedicle screw at the same level. The L-3 pedicle rescue screws retained an average of $65 \%$ of the original cortical screw pullout strength, again with good raw pullout values. There were no significant differences in stiffness testing in flexion/extension, lateral bending, and axial rotation between the initial cortical screw construct and the subsequent hybrid construct with pedicle rescue screws. Knowing that there is a viable rescue option may increase surgeon comfort in trying the cortical trajectory screws in the appropriate circumstances.

A potential limitation of this study is that only a small number of specimens were tested. Clearly, if the sample size were increased to a large enough number, then eventually a statistically significant difference could be detected. However, no threshold values have been established for what constitutes a clinically or biologically meaningful difference for measurements such as stiffness or pullout strength; thus, a meaningful power analysis cannot 
TABLE 1. Stiffness of L3-4 segment following instrumentation*

\begin{tabular}{cc}
\hline \multicolumn{1}{c}{ Group } & Mean Stiffness (Nm/degree) \\
\hline Flexion/extension & \\
\hline Pedicle $w /$ rods & $9.64 \pm 1.71$ \\
\hline Cortical $w /$ rods & $13.42 \pm 2.80$ \\
\hline Cortical rescue $w /$ rods & $13.14 \pm 2.30$ \\
\hline Pedicle rescue $w /$ rods & $10.99 \pm 3.45$ \\
\hline Lateral bending & \\
\hline Pedicle $w /$ rods & $8.63 \pm 2.50$ \\
\hline Cortical $w /$ rods & $6.56 \pm 1.68$ \\
\hline Cortical rescue $w /$ rods & $7.19 \pm 1.78$ \\
\hline Pedicle rescue $w /$ rods & $6.36 \pm 1.60$ \\
\hline Axial rotation & \\
\hline Pedicle $w /$ rods & $8.94 \pm 4.19$ \\
\hline Cortical $w /$ rods & $8.75 \pm 2.84$ \\
\hline Cortical rescue $w /$ rods & $8.61 \pm 4.33$ \\
\hline Pedicle rescue $w /$ rods & $9.31 \pm 5.68$ \\
\hline
\end{tabular}

* Values represent the mean \pm standard deviation.
TABLE 2. Comparison between construct types in stiffness at L3-4 following instrumentation

\begin{tabular}{cc}
\hline \multicolumn{1}{c}{ Group Comparison } & p Value \\
\hline Flexion/extension & \\
\hline Pedicle vs cortical rescue & 0.06 \\
\hline Cortical vs pedicle rescue & 0.08 \\
\hline Pedicle rescue vs cortical rescue & 0.22 \\
\hline Lateral bending & \\
\hline Pedicle vs cortical rescue & 0.02 \\
\hline Cortical vs pedicle rescue & 0.58 \\
\hline Pedicle rescue vs cortical rescue & 0.54 \\
\hline Axial rotation & \\
\hline Pedicle vs cortical rescue & 0.13 \\
\hline Cortical vs pedicle rescue & 0.65 \\
\hline Pedicle rescue vs cortical rescue & 0.81 \\
\hline
\end{tabular}

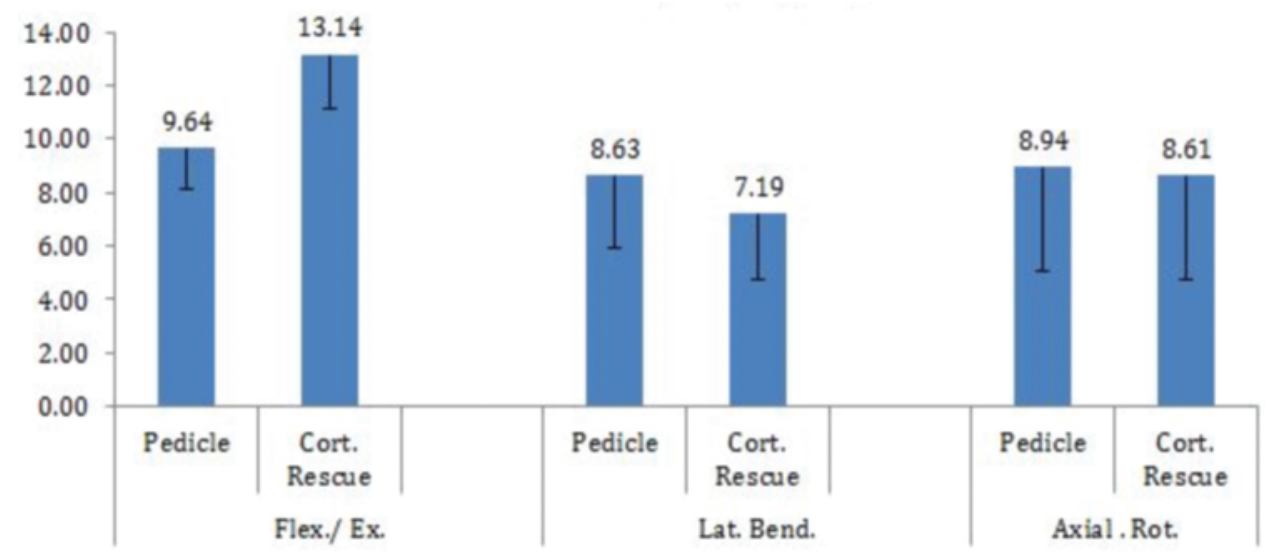

FIG. 5. Initial pedicle screw construct versus cortical (Cort.) screw rescue construct. Axial. Rot. = axial rotation; Flex./ Ex. = flexion/extension; Lat. Bend. = lateral bending. The y-axis represents construct stiffness measured in Nm/degree. Figure is available in color online only.

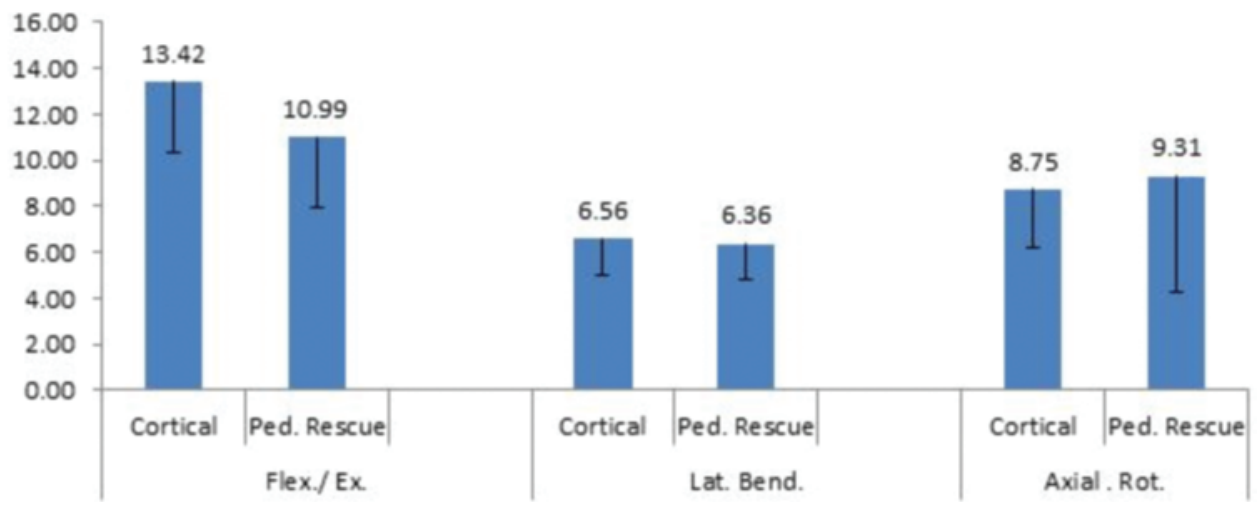

FIG. 6. Initial cortical screw construct versus pedicle (Ped.) screw rescue construct. The y-axis represents construct stiffness measured in Nm/degree. Figure is available in color online only. 


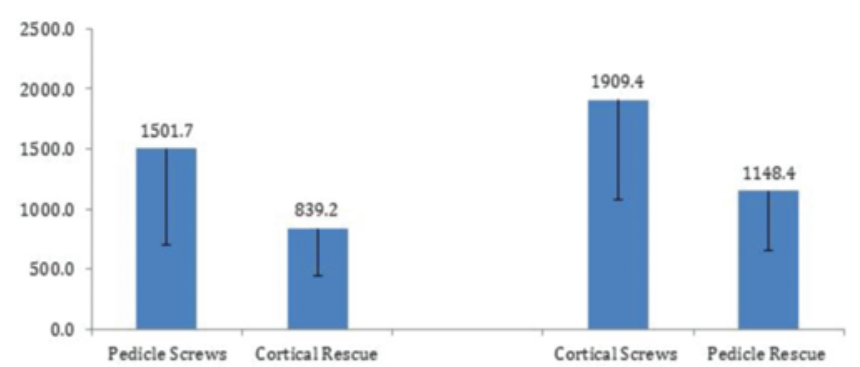

FIG. 7. Pullout strength (y-axis represents $N$ ). Figure is available in color online only.

be performed. Future studies might focus on clinical and radiographic outcomes for screws placed in the standard pedicle versus cortical trajectories, both in the primary and revision settings, and on direct biomechanical testing of various salvage techniques.

\section{Conclusions}

In summary, cortical trajectory screws may be used as a primary mode of fixation; however, data in this study support their use as a rescue option in the setting of a failed or compromised pedicle screw construct in the lumbar spine without the need for augmentation or additional levels of fixation and fusion. Future clinical studies are needed to corroborate the theoretical and in vitro benefits noted in this study.

\section{Acknowledgment}

Implants were donated by Medtronic Inc.

\section{References}

1. Bishop FS, Samuelson MM, Finn MA, Bachus KN, Brodke DS, Schmidt MH: The biomechanical contribution of varying posterior constructs following anterior thoracolumbar corpectomy and reconstruction. J Neurosurg Spine 13:234239, 2010

2. Brodke DS, Bachus KN, Mohr RA, Nguyen BK: Segmental pedicle screw fixation or cross-links in multilevel lumbar constructs. a biomechanical analysis. Spine J 1:373-379, 2001

3. Brodke DS, Gollogly S, Alexander Mohr R, Nguyen BK, Dailey AT, Bachus KN: Dynamic cervical plates: biomechanical evaluation of load sharing and stiffness. Spine (Phila Pa 1976) 26:1324-1329, 2001

4. Brodke DS, Klimo P Jr, Bachus KN, Braun JT, Dailey AT: Anterior cervical fixation: analysis of load-sharing and stability with use of static and dynamic plates. J Bone Joint Surg Am 88:1566-1573, 2006

5. Chrea B, Malempati H, Campbell JR, Khan S, Ching RP, Lee MJ: Enhancing pedicle screw fixation in the lumbar spine using allograft bone plug interference fixation. J Spinal Disord Tech 27:E81-E87, 2014

6. Derincek A, Wu C, Mehbod A, Transfeldt EE: Biomechanical comparison of anatomic trajectory pedicle screw versus injectable calcium sulfate graft-augmented pedicle screw for salvage in cadaveric thoracic bone. J Spinal Disord Tech 19:286-291, 2006
7. Esses SI, Sachs BL, Dreyzin V: Complications associated with the technique of pedicle screw fixation. A selected survey of ABS members. Spine 18:2231-2239, 1993

8. Fassett DR, Apfelbaum R, Clark R, Bachus KN, Brodke DS: Biomechanical analysis of a new concept: an add-on dynamic extension plate for adjacent-level anterior cervical fusion. Spine (Phila Pa 1976) 30:2523-2529, 2005

9. Finn MA, Brodke DS, Daubs M, Patel A, Bachus KN: Local and global subaxial cervical spine biomechanics after singlelevel fusion or cervical arthroplasty. Eur Spine J 18:15201527, 2009

10. Finn MA, Samuelson MM, Bishop F, Bachus KN, Brodke DS: Two-level noncontiguous versus three-level anterior cervical discectomy and fusion: a biomechanical comparison. Spine (Phila Pa 1976) 36:448-453, 2011

11. Hirano T, Hasegawa K, Takahashi HE, Uchiyama S, Hara T, Washio T, et al: Structural characteristics of the pedicle and its role in screw stability. Spine (Phila Pa 1976) 22:25042510,1997

12. Hu MH, Wu HT, Chang MC, Yu WK, Wang ST, Liu CL: Polymethylmethacrylate augmentation of the pedicle screw: the cement distribution in the vertebral body. Eur Spine J 20:1281-1288, 2011

13. Iannotti JP, Frangiamore SJ: Fate of large structural allograft for treatment of severe uncontained glenoid bone deficiency. J Shoulder Elbow Surg 21:765-771, 2012

14. Klein SA, Glassman SD, Dimar JR II, Voor MJ: Evaluation of the fixation and strength of a "rescue" revision pedicle screw. J Spinal Disord Tech 15:100-104, 2002

15. Lattig F: Bone cement augmentation in the prevention of adjacent segment failure after multilevel adult deformity fusion. J Spinal Disord Tech 22:439-443, 2009

16. Lehman RA Jr, Kuklo TR: Use of the anatomic trajectory for thoracic pedicle screw salvage after failure/violation using the straight-forward technique: a biomechanical analysis. Spine (Phila Pa 1976) 28:2072-2077, 2003

17. Lehman RA Jr, Polly DW Jr, Kuklo TR, Cunningham B, Kirk KL, Belmont PJ Jr: Straight-forward versus anatomic trajectory technique of thoracic pedicle screw fixation: a biomechanical analysis. Spine (Phila Pa 1976) 28:2058-2065, 2003

18. Lotz JC, Hu SS, Chiu DF, Yu M, Colliou O, Poser RD: Carbonated apatite cement augmentation of pedicle screw fixation in the lumbar spine. Spine (Phila Pa 1976) 22:27162723, 1997

19. Matsukawa K, Yato Y, Kato T, Imabayashi H, Asazuma T, Nemoto K: In vivo analysis of insertional torque during pedicle screwing using cortical bone trajectory technique. Spine (Phila Pa 1976) 39:E240-E245, 2014

20. Matsukawa K, Yato Y, Nemoto O, Imabayashi H, Asazuma T, Nemoto K: Morphometric measurement of cortical bone trajectory for lumbar pedicle screw insertion using computed tomography. J Spinal Disord Tech 26:E248-E253, 2013

21. Misenhimer GR, Peek RD, Wiltse LL, Rothman SL, Widell EH Jr: Anatomic analysis of pedicle cortical and cancellous diameter as related to screw size. Spine (Phila Pa 1976) 14:367-372, 1989

22. Moore DC, Maitra RS, Farjo LA, Graziano GP, Goldstein SA: Restoration of pedicle screw fixation with an in situ setting calcium phosphate cement. Spine (Phila Pa 1976) 22:1696-1705, 1997

23. Motzkin NE, Chao EY, An KN, Wikenheiser MA, Lewallen DG: Pull-out strength of screws from polymethylmethacrylate cement. J Bone Joint Surg Br 76:320-323, 1994

24. Perez-Orribo L, Kalb S, Reyes PM, Chang SW, Crawford NR: Biomechanics of lumbar cortical screw-rod fixation versus pedicle screw-rod fixation with and without interbody support. Spine (Phila Pa 1976) 38:635-641, 2013

25. Pfeifer BA, Krag MH, Johnson C: Repair of failed trans- 
pedicle screw fixation. A biomechanical study comparing polymethylmethacrylate, milled bone, and matchstick bone reconstruction. Spine (Phila Pa 1976) 19:350-353, 1994

26. Polly DW Jr, Orchowski JR, Ellenbogen RG: Revision pedicle screws. Bigger, longer shims - what is best? Spine (Phila Pa 1976) 23:1374-1379, 1998

27. Santoni BG, Hynes RA, McGilvray KC, Rodriguez-Canessa G, Lyons AS, Henson MA, et al: Cortical bone trajectory for lumbar pedicle screws. Spine J 9:366-373, 2009

28. Slucky AV, Brodke DS, Bachus KN, Droge JA, Braun JT: Less invasive posterior fixation method following transforaminal lumbar interbody fusion: a biomechanical analysis. Spine J 6:78-85, 2006

29. Wilkes RA, Mackinnon JG, Thomas WG: Neurological deterioration after cement injection into a vertebral body. J Bone Joint Surg Br 76:155, 1994

30. Yerby SA, Toh E, McLain RF: Revision of failed pedicle screws using hydroxyapatite cement. A biomechanical analysis. Spine (Phila Pa 1976) 23:1657-1661, 1998

31. Yüksel KZ, Adams MS, Chamberlain RH, Potocnjak M, Park SC, Sonntag VKH, et al: Pullout resistance of thoracic extrapedicular screws used as a salvage procedure. Spine J 7:286-291, 2007

\section{Author Contributions}

Conception and design: Brodke, Calvert, Bachus, Lawrence. Acquisition of data: Brodke, Calvert, Abtahi, Bachus. Analysis and interpretation of data: all authors. Drafting the article: all authors. Critically revising the article: all authors. Reviewed submitted version of manuscript: all authors. Approved the final version of the manuscript on behalf of all authors: Brodke. Statistical analysis: Brodke, Calvert, Abtahi, Bachus. Administrative/techni$\mathrm{cal} /$ material support: Brodke, Bachus, Lawrence. Study supervision: Brodke, Calvert, Bachus, Lawrence.

\section{Correspondence}

Darrel S. Brodke, Department of Orthopaedics, University of Utah, 590 Wakara Way, Salt Lake City, UT 84108. email: darrel. brodke@hsc.utah.edu. 